\title{
Age-related increase in amyloid plaque burden is associated with impairment in conditioned fear memory in CRND8 mouse model of amyloidosis
}

\author{
Amanda Hanna ${ }^{2}$, Kayleigh Iremonger ${ }^{3}$, Pritam Das ${ }^{2}$, Dennis Dickson² ${ }^{2}$ Todd Golde ${ }^{1}$ and Christopher Janus $^{1 *}$
}

\begin{abstract}
Introduction: The current pathological confirmation of the diagnosis of Alzheimer's disease (AD) is still based on postmortem identification of parenchymal amyloid beta (A $\beta$ ) plaques, intra-neuronal neurofibrillary tangles, and neuronal loss. The memory deficits that are present in the early stages of AD are linked to the dysfunction of structures in the entorhinal cortex and limbic system, especially the hippocampus and amygdala. Using the CRND8 transgenic mouse model of amyloidosis, which over-expresses a mutant human amyloid precursor protein (APP) gene, we evaluated hippocampus-dependent contextual and amygdala-dependent tone fear conditioned (FC) memory, and investigated the relationship between the fear memory indices and A $\beta$ plaque burden.

Methods: Mice were tested at three, six, and 12 months of age, which corresponds to early, mild, and severe $A \beta$ plaque deposition, following a cross-sectional experimental design. We used a delay version of the fear conditioning paradigm in which tone stimulus was co-terminated with foot-shocks during exploration of the training chamber. The $A \beta$ plaque burden was evaluated at each age after the completion of the behavioral tests.

Results: CRDN8 mice showed context fear memory comparable to control mice at three and six months, but were significantly impaired at 12 months of age. In contrast, the tone fear memory was significantly impaired in the model at each age of testing. The $A \beta$ plaque burden significantly increased with age, and was correlated with the overall impairment in context and tone fear memory in the CRND8 mice within the studied age.

Conclusions: Our data extend previous studies showing that other APP mouse models exhibit impairment in fear conditioned memory, by demonstrating that this impairment is progressive and correlates well with an overall increase in $A \beta$ burden. Also, the demonstrated greater sensitivity of the tone conditioning test in the identification of age dependent differences between CRND8 and control mice suggests that this paradigm might be particularly suitable in studies evaluating potential therapeutics related to memory improvement in mouse models of amyloidosis.
\end{abstract}

\section{Introduction}

Alzheimer's disease (AD) is the leading cause of dementia in the elderly, affecting more than 35 million people worldwide [1]. Currently, confirmation of a clinical diagnosis of $\mathrm{AD}$ still requires post mortem identification of parenchymal amyloid beta $(A \beta)$ deposits and intra-neuronal neurofibrillary tangles composed of abnormally phosphorylated tau protein [2-5] and severe loss of brain tissue [6-8].

\footnotetext{
*Correspondence: cjanus@ufl.edu

${ }^{1}$ Center for Translational Research in Neurodegenerative Disease and Department of Neuroscience, University of Florida, 1275 Center Dr.,

Gainesville, FL, 32610, USA

Full list of author information is available at the end of the article
}

In the near future, cerebrospinal fluid (CSF) measures of $A \beta$ and tau or amyloid imaging may be utilized to provide pre-mortem confirmation of the AD diagnosis. Senile amyloid plaques are found in large numbers in the limbic system, including amygdala (AD is often referred to as limbic dementia' [9]), hippocampus, and associative cortices which are affected first during the disease progression [10-18].

Transgenic mice, over-expressing the mutated human amyloid precursor protein $(A P P)$ gene, provide a valuable tool for investigating the associations between amyloidosis, neuronal dysfunction, and cognitive impairment [19-23]. In the present study, we investigated the age-progressing

\section{Biomed Central}


A $\beta$ plaque burden and corresponding changes in conditioned fear memory in a transgenic mouse model, denoted CRND8. Previous characterizations of this model revealed impairments in spatial reference [24-26] and spatial working [27] memory, and in associative learning of conditioned taste aversion [28]. Other abnormalities reported in CRND8 mice included increased stereotypic behavior [29], brain inflammation [30] and increased sensitivity to experimentally induced seizures [31].

In our study, we adopted a delay fear conditioning (FC) training paradigm in which an initially neutral conditioned stimulus (CS), usually a tone, is simultaneously presented or co-terminates with an unconditioned stimulus (US), typically a foot-shock [32,33]. Following the CS-US pairing (s), mice display an anti-predatory freezing response both in the presence of a salient CS (tone conditioned fear memory) or when being placed in the original training chamber in which they experienced the US (contextual fear conditioning memory). It has been shown that the contextual fear memory depends on an intact hippocampus [34,35], while the cued fear memory depends on an intact amygdala [36,37].

The aim of the present study was to evaluate the contextual and cued fear memory of CRND8 mice at the age of three, six, and 12 months, which corresponded to the onset of low, moderate, and severe $A \beta$ plaque deposition in the brain of these mice [38], and to associate the $A \beta$ plaque burden with the context and tone memory indices. The results demonstrated that the $A \beta$ plaque burden significantly increased within the studied age range, and it was significantly associated with an overall impairment in contextual and tone fear memory in CRND8 mice. The oldest, 12 month-old, CRND8 mice showed impairment in both types of memory. While the context memory of the younger, three and six month-old, CRND8 mice was comparable to control littermates, the tone fear memory of the CRND8 mice was significantly impaired at each age of testing. The apparent increase in the sensitivity of the detection of age-dependent onset of memory impairment using tone fear conditioning makes this test an attractive potential diagnostic tool during evaluation of the efficacy of potential therapeutics on memory function in the CRND8 mouse model.

\section{Materials and methods Mice}

The transgenic CRND8 mice over-express mutant forms of human APP genes (Swedish; KM670/671NL + Indiana; $V 717 F)[26,38]$ implicated in AD $[39,40]$. This model shows rapid onset of extra-cellular $\mathrm{A} \beta$ deposits at 2.5 to 3 months of age, with coinciding impairment in spatial reference memory [26]. Dense-core A $\beta$ plaques and neuritic pathology appear at five months [38].
Three cohorts of transgenic (Tg) CRND8 and nontransgenic (nTg) littermates (hybrid genetic background, $\mathrm{C} 57 \mathrm{BL} / 6 / / \mathrm{C} 3 \mathrm{H})$ at ages three $(\mathrm{N}=27,13 / 14 \mathrm{Tg} / \mathrm{nTg})$, six $(\mathrm{N}=28,11 / 17 \mathrm{Tg} / \mathrm{nTg})$, and $12(\mathrm{~N}=24,11 / 13 \mathrm{Tg} / \mathrm{nTg})$ months were used. The physical condition and sensorimotor propensities of the CRND8 mice did not differ from their control nTg littermates within the studied age range as evaluated in the SHIRPA (SmithKline Beecham Pharmaceuticals; Harwell, MRC Mouse Genome Centre and Mammalian Genetics Unit; Imperial College School of Medicine at St Mary's; Royal London Hospital, St Bartholomew's and the Royal London School of Medicine; Phenotype Assessment) phenotyping screen (data not shown). The cohorts within each genotype were female biased (median for males $=3.5$, for females $=9$ ). The mice were genotyped at weaning by analysis of tail DNA with a human APP hybridization probe, as described previously [38]. They were housed in same-sex groups of two to four under standard laboratory conditions (12:12 hours light/ dark cycle, lights on at 0600 hours) with a room temperature of $21^{\circ} \mathrm{C}$, and water and food available ad libitum. All tests were performed during the light phase between 09:00 and 14:00 hours. All procedures were approved by the Institutional Animal Care and Use Committee of Mayo Clinic Jacksonville and are in accordance with Association for Assessment and Accreditation of Laboratory Animal Care International (AAALAC) and the National Institutes of Health Guide for the Care and Use of Laboratory Animals guidelines.

\section{Primary neurological and sensorimotor examination}

The SHIRPA protocol $[41,42]$ involves a series of tests assessing the physical condition of the mice. The following phenotypes are measured: (1) body position in a cage, respiration, tremor, transfer arousal, palpebral closure, piloerection, (2) reflexes - touch escape, pinna reflex, trunk curl, limb grasping, visual placing, negative geotaxis and righting reflex, and (3) grip strength. The screen takes altogether about five to seven minutes per mouse.

\section{Fear conditioning test}

The conditioning procedure was carried out in four identical chambers $(25.3 \mathrm{~L} \times 29.5 \mathrm{~W} \times 29.5 \mathrm{H} \mathrm{cm}$; Coulbourn Instruments.). The total floor area of each chamber was $746 \mathrm{~cm}^{2}$. The chambers were constructed from aluminum (sidewalls and ceiling) and Plexiglas (rear and front walls). They were placed individually in sound-attenuated cabinets with black inside walls (interior dimensions: 43.3L $\times$ $55.3 \mathrm{~W} \times 58.5 \mathrm{H} \mathrm{cm}$; Coulbourn Instruments.), which were located in a dedicated room. A ventilation fan in each cabinet provided $50 \mathrm{~dB}$ of background noise, and a $24 \mathrm{~V}$ DC white light, mounted on a wall of each chamber, provided illumination (65 lux at the floor level). A speaker 
mounted in the wall opposite to the light delivered an acoustic CS. The floor of each chamber, which consisted of 26 stainless steel rods ( $3 \mathrm{~mm}$ in diameter) spaced 11 $\mathrm{mm}$ center to center, was wired to a precision-regulated shocker (H13-15, Coulbourn Instruments). A camera mounted above the chamber recorded mouse activity. Conditioning was assessed by the analysis of the fear response expressed as freezing behavior with the aid of the FreezeFrame program (v. 3.06, Actimetrics). Freezing was defined as the cessation of all movements other than respiratory activity [43].

\section{Conditioning procedure and memory tests}

Mice were exposed to the context of a training chamber and a tone, both initially novel and neutral stimuli, in one training session. They were transported in squads of four in individual containers filled with home cage bedding and placed singly in the conditioning chamber. During training, the mice received two pairings between a tone $(80 \mathrm{~dB}$, pulse (six clicks per second (c.p.s)), 30 seconds duration) and a $0.45 \mathrm{~mA}$ foot shock (two seconds duration, co-terminated with a tone). The first CS-US pairing was delivered at the end of 120 seconds of the initial exploration of the chamber, and the second following a 60-second interval. After the second CS-US pairing the mice were given a 60 -second post-training period. The total duration of the training session was 300 seconds. After a day of recovery, the mice were returned to their respective conditioning chambers and tested for fear-induced freezing to the context in which they received foot shocks. The test, carried out in an extinction mode with no shock administered, lasted 300 seconds. The following day, the mice were tested for the association between the tone and the footshock in a modified chamber. The floor and the walls of the chamber were replaced with plastic inserts (opaque white for the floor, and semi-transparent white at the front and opaque green at the back for the walls), which also eliminated corners in the chamber. The total floor area of the modified chamber was about $671 \mathrm{~cm}^{2}$. A Petri dish containing a drop of a Pure Lemon Extract (McCormick) was placed underneath the floor of each chamber to provide a distinct novel odor in the chamber. The above modifications did not change the light intensity in the chamber. The tone test lasted 360 seconds. During the first 180 seconds the mice were allowed to explore the new environment and during the second 180 seconds a tone, with the same characteristics as the tone used during training, was delivered. Mice activity was recorded during all tests.

\section{Quantification of $A \beta$ deposition}

At the end of the experiment, the mice were sacrificed and their brains were removed. One hemi-brain was submerged in $10 \%$ neutrally buffered formalin for immunohistochemical analysis of $\mathrm{A} \beta$ plaque burden. The remaining hemisphere of the brain was snap frozen and stored at $-80^{\circ} \mathrm{C}$ for further analysis. Paraffin, coronal $5 \mu \mathrm{m}$ sections were affixed to Fisher brand Superfrost/ Plus slides to ensure adhesion. Brain sections (10 to 12 sections/set) cut at $30 \mu \mathrm{m}$ intervals within the range of $-1.22 \mathrm{~mm}$ to $-3.08 \mathrm{~mm}$ from the bregma [44], including the hippocampus and amygdala, were used for analyses. All slides were deparaffinized and immunostained with the pan $\mathrm{A} \beta 1$ to 16 (33.1.1) antibody (dilution $1: 5000)$ to visualize both diffuse and core $A \beta$ deposits. A separate set of slides was stained by anti- A $\beta 40$ (MM3213.1.1) antibody (dilution 1:2000) in order to selectively quantify core $A \beta$ deposits. Stained sections were scanned with a high resolution, whole slide imaging system $(0.46 \mu \mathrm{m} /$ pixel with $20 \mathrm{X}$ objective lens, ScanScope $^{\mathrm{TM}}$ XT, Aperio Technologies, Inc. Vista, CA, USA). The images were viewed in an ImageScope ${ }^{\mathrm{TM}}$ viewer ( $\mathrm{v}$. 10) and the $A \beta$-positive staining was detected using an automated image analysis system by applying a color deconvolution method [45] within the Hue, Saturation, Intensity (HSI) model (Color Deconvolution algorithm, Aperio Technologies, Inc., settings: hue value and width $=0.1$ and 0.3 , respectively, and saturation threshold $=$ 0.04). The area of the brain including the cortex, hippocampus, and amydgala were outlined according to the mouse atlas [44], and the $A \beta$ burden was expressed as the percent of outlined area stained positively for $A \beta$. Background staining was determined in the area of basal ganglia, which was devoid of $\mathrm{A} \beta$-positive staining, and was set to a pixel value of 40 .

\section{Data and statistical analyses}

Since the experimental design included two between subjects factors: genotype and age, we followed two a priori identified approaches to data analysis. In the first, we compared the conditioned fear memory between the genotypes within the tested age range, followed by post-hoc analysis at each age. These analyses provided answers to agerelated differences in memory scores between transgenic and control mice. The second analytical approach focused on the age-related changes in context and tone fear memory within each genotype. While the cross-sectional design of the study did not eliminate between subjects variability in the evaluation of the age-related changes within each genotype, thus decreasing slightly the sensitivity of the study, it allowed us to evaluate the $\mathrm{A} \beta$ pathology at each testing age and relate it to the obtained memory scores. Due to significantly female-biased groups, the analysis of possible sex effects was not performed. The overall analysis of the experiment was done by a factorial analysis of variance (ANOVA) with genotype and age as between subject factors. Where appropriate, simple effects were evaluated using one-way ANOVA. In analyses requiring 
multiple comparisons between means, the Bonferroni adjustment of $\alpha$ level minimizing Type I (family-wise) error rate was used [46]. A priori comparisons were performed using the Bonferroni $t$ test (MODLSD), and posthoc multiple pair-wise comparisons were done using the Student-Newman-Keuls (SNK) test [46]. All statistical analyses were done using the Statistical Package for Social Sciences (SPSS Inc. Chicago) version 19 for Macintosh. Comparisons between two independent groups were done using a Student t-test. Spearman's rank correlation was used to assess the associations between $A \beta$ burden and freezing behavior, and partial correlation was used to evaluate associations while controlling for the effect of genotype. Due to the nonparametric nature of the data obtained in the SHIRPA screen, these data were analyzed using the $\chi^{2}$ test [47]. The critical $\alpha$ level was set to 0.05 in all analyses. All values in the text and figures represent means \pm the standard error of the mean (SEM).

\section{Results}

\section{Training: exploration and response to foot-shock}

There was no difference between the CRND8 and control $\mathrm{nTg}$ mice in the exploratory activity preceding the first CS-US presentation (data not shown). All mice spent, on average, less than $1 \%$ of the time on spontaneous pauses during the120 second exploration. Overall, older mice paused longer $(\mathrm{F}(2,73)=4.1, P<0.05)$, mainly due to longer breaks in motor activity of 12-month-old CRND8 mice $(\mathrm{F}(2,73)=5.8, P<0.01$, genotype by age interaction) Twelve-month-old CRND8 mice spent $2.6 \% \pm 0.9$ of the time immobile, which was significantly longer than their younger counterparts $(P<0.01$ and $P<0.05$ for the comparisons with three- and six-month-old mice, respectively, Bonferroni t-test), but this amounted only to about three seconds of immobility during exploration. There was no difference in activity between the age cohorts of $\mathrm{nTg}$ mice.

The immediate freezing response to foot-shock was significantly lower in CRND8 mice than in nTg littermates (F $(1,73)=29.1, P<0.001$, genotype effect, Figure $1 \mathrm{~A})$. Also, the oldest mice of both genotypes tended to show less immediate freezing than younger mice $(\mathrm{F}(2,73)=3.0, P=$ 0.054 , age effect, Figure 1A). The examination of the effect of age on immediate freezing within each genotype revealed no significant trends in the decrease of immediate freezing in $\mathrm{nTg}$ or CRND8 mice $(\mathrm{F}(1,41)=2.1$, NS and $\mathrm{F}$ $(1,32)=2.1$, NS, respectively, ANOVA simple effects $)$, confirming a weak effect of age on immediate freezing.

\section{Context fear memory}

The CRND8 mice showed a significantly lower freezing response during the context test than $\mathrm{nTg}$ littermates (F $(1,72)=7.3, P<0.01$, genotype effect, Figure $1 \mathrm{~B})$. Overall older mice showed weaker context memory $(\mathrm{F}(2,31)=3.8$, $P<0.05$, age effect). Post-hoc comparisons revealed that 12-month-old CRND8 mice froze significantly less than their nTg littermates $(\mathrm{t}(22)=3.4, P<0.01)$; however, the contextual memory of three- and six-month-old CRND8 and $\mathrm{nTg}$ mice was comparable. The freezing rate of the mice during the context test was not significantly associated with the duration of pauses during initial exploration of the training chamber $\left(\mathrm{r}^{2}(74)=0.02\right.$, NS). The analysis of age-related changes in contextual fear memory within each genotype revealed a significant decrease in freezing to training context in CRND8 mice $(\mathrm{F}(1,32)=3.7$, $P<0.05$, ANOVA simple effects). Post-hoc comparisons demonstrated that 12-month-old CRND8 mice showed a significantly lower context memory than three-month-old mice $(P<0.05$, Bonferroni t-test), but not than six-monthold counterparts. The changes in context memory of $\mathrm{nTg}$ control mice due to age were not significant $(\mathrm{F}(1,41)=0.4$, NS, ANOVA, simple effects).

\section{Tone fear memory}

The average percent of freezing time displayed by mice during the tone fear conditioning test is presented in Figure 1C. Overall, CRND8 mice froze less during the whole test than $\mathrm{nTg}$ mice $(\mathrm{F}(1,73)=36.2, P<0.001$, genotype effect). Also, all mice froze longer during the presentation of the tone $(\mathrm{F}(1,73)=208.2, P<0.001$, tone effect); however the level of freezing to tone depended on genotype $(\mathrm{F}(1,73)=33.4, P<0.001$, genotype $\times$ tone interaction) and age $(\mathrm{F}(2,73)=3.3, P<0.05$, age $\times$ tone interaction).

The post-hoc analysis revealed that CRND8 mice froze significantly less during the exploration of the altered training chamber than $\mathrm{nTg}$ mice $(\mathrm{F}(1,73)=12.6, P<$ 0.001 , genotype effect, Figure $1 \mathrm{C}$ left panel). The six- and 12-month-old CRND8 mice froze less than their threemonth-old counterparts $(P=0.1$ and $P=0.07$, respectively, Bonferroni t-test). The freezing rate of threemonth-old CRND8 mice was comparable to the freezing rate of $\mathrm{nTg}$ mice, which showed comparable exploration of altered context at all ages.

Overall, tone fear memory of CRND8 mice was impaired $(\mathrm{F}(1,73)=43.9, P<0.001$, Figure $1 \mathrm{C}$ right panel, genotype effect), and was weaker in older mice ( $F$ $(2,73)=3.3, P<0.05$, age effect). Post-hoc analysis revealed that CRND8 mice showed a weaker memory than their nTg controls at each age of testing $(\mathrm{t}(25)=$ $3.2, P<0.01, \mathrm{t}(26)=3.4, P<0.01$, and $\mathrm{t}(16)=5.4, P<$ 0.001 , for three-, six-, and 12 month-old age cohorts, respectively, Figure $1 \mathrm{C}$, right panel). Within-genotypes comparisons revealed that the tone memory of CRND8 mice decreased with age $(\mathrm{F}(2,32)=5.7, P<0.01$, ANOVA, simple effects), mainly due to lower freezing in 12-month-old mice $(P<0.01$ and $P<0.05$ for the comparison with three- and six-month-old counterparts, Bonferroni t-test). Tone fear memory of nTg mice was 

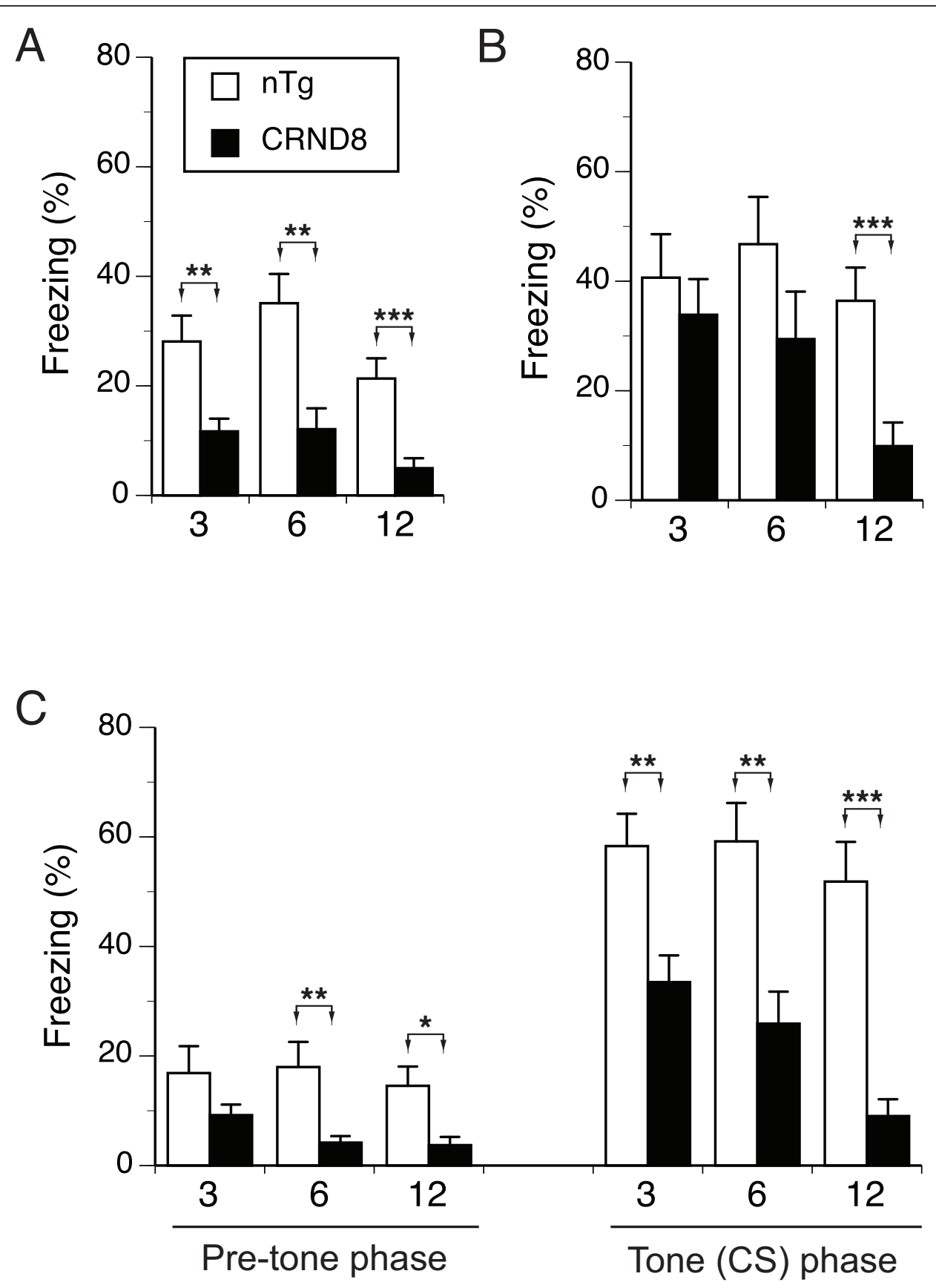

Figure 1 Mean ( \pm SEM) percent of freezing by CRND8 mice and their non-transgenic (nTg) littermates at three, six, and 12 months of age. (A) CRND8 mice showed significantly lower rates of freezing as compared to nTg mice immediately following the presentation of a foot shock during training ( $P<0.001$ - genotype effect). (B) Overall, the context memory of CRND8 mice was impaired as compared to control nTg mice $(P<0.01$ - genotype effect). No differences in context memory were found between $\mathrm{nTg}$ and $\mathrm{Tg}$ mice at three and six months, but at $12-$ months the CRND8 mice were significantly impaired (post-hoc Bonferroni t-test). (C) CRND8 mice froze significantly less than nTg mice during the pre-tone (left panel) and the tone (right panel) phases of the test. The CRND8 mice showed significant impairment in tone fear memory at each age of testing (right panel). Three, six, 12 on the abscissae refer to the age of testing. ${ }^{*} P<0.02,{ }^{* *} P<0.01,{ }^{* * *} P<0.001$.

not affected by age $(\mathrm{F}(1,41)=0.3$, NS, ANOVA, simple effects).

Of interest is that the significant dissociation between age-dependent onset of the impairment in the context and tone memory was caused by stronger tone memory of nTg mice as compared to the strength of their context memory at each age $(\mathrm{t}(13)=-2.8, P<0.02 ; \mathrm{t}(16)=$ $-2.4, P<0.05 ; \mathrm{t}(12)=-2.7, P<0.02$, for three, six and 
12 month tests, respectively). The tone and context memory of CRND8 mice were comparable (Figure 1B and $1 \mathrm{C}$ right panel).

\section{$A \beta$ plaque burden increases with age in CRND8 mice}

We previously demonstrated that amyloid plaque burden was significantly correlated with sodium dodecyl sulfate (SDS-) soluble and formic acid (FA-) extractable $A \beta$ fractions in the CRND8 model, and that both biochemical and histo-pathological analyses of $A \beta$ led to the same interpretations of cognitive impairment in multiple memory systems [24].

The representative pictures of the $A \beta$ plaque burden in the brain of three-, six-, and 12-month-old CRND8 mice are shown in Figure 2. The $\mathrm{A} \beta$ plague burden increased with age $\left(\mathrm{r}_{S}=0.94, P<0.001\right)$, differentiating the age cohorts of CRND8 mice $(\mathrm{F}(2,26)=100.6, P<$ 0.001, Figure 3). Post-hoc comparisons revealed differences in $\mathrm{A} \beta$ burden between all tested age groups $(3<6$ $<12$, Ps $<0.01$, Bonferroni t-test, Figure $3 \mathrm{~A}$ ). A $\beta$ burden at younger ages was most prominent in the cortical, hippocampal, and amygdala regions (Figure $2 \mathrm{AB}$ ); at 12 months the $A \beta$ deposits were observed in the whole brain, including thalamic, hypothalamic and caudate/ amygdala regions (Figure $2 \mathrm{C}$ ). We found a strong positive correlation between the $A \beta$ plaque burden evaluated by staining with pan $A \beta$ 1-16 antibody and the total number of $A \beta$ dense core deposits stained by antiA $\beta 40$ antibody $\left(r_{S}=0.9, P<0.001\right)$. Consequently, the dense-core $A \beta$ burden is not reported.

\section{Increase in $A \beta$ plaque burden impairs context and tone fear memory}

The increased-with-age levels of $A \beta$ plaque burden were correlated with the impairment in context and tone fear memory in CRBD8 mice $\left(\mathrm{r}_{S}=-0.43, \mathrm{P}<0.05\right.$ for context (Figure $3 \mathrm{~B}$ ), and $\mathrm{r}_{S}=-0.40, P<0.05$ for tone (Figure $3 \mathrm{C}$ ) memory). No association was found between $A \beta$ plaque burden and immediate freezing following foot-shock or freezing during the pre-tone phase of the tone test.

Next, we investigated whether the variability in the $A \beta$ plaque burden at each age of testing also reflects inverse association with context and tone fear memory. We found that variability in $A \beta$ plaque burden (expressed by the coefficient of variation $(\mathrm{CV})$ ) increased with age, from $17 \%$ at three months to $34 \%$, and $27 \%$ at six and 12 months, respectively. Moreover, the variability in memory scores of CRND8 mice differed from the variability in memory of nTg littermates. While the variance in memory scores of nTg mice was low and comparable across age groups $(73 \%, 76 \%, 60 \%$, and $38 \%, 49 \%, 50 \%$ for three, six, and 12 month context and tone memory, respectively), the variability in memory scores of CRND8 mice was higher, reaching high variance $(\mathrm{CV}>100 \%)$ at the

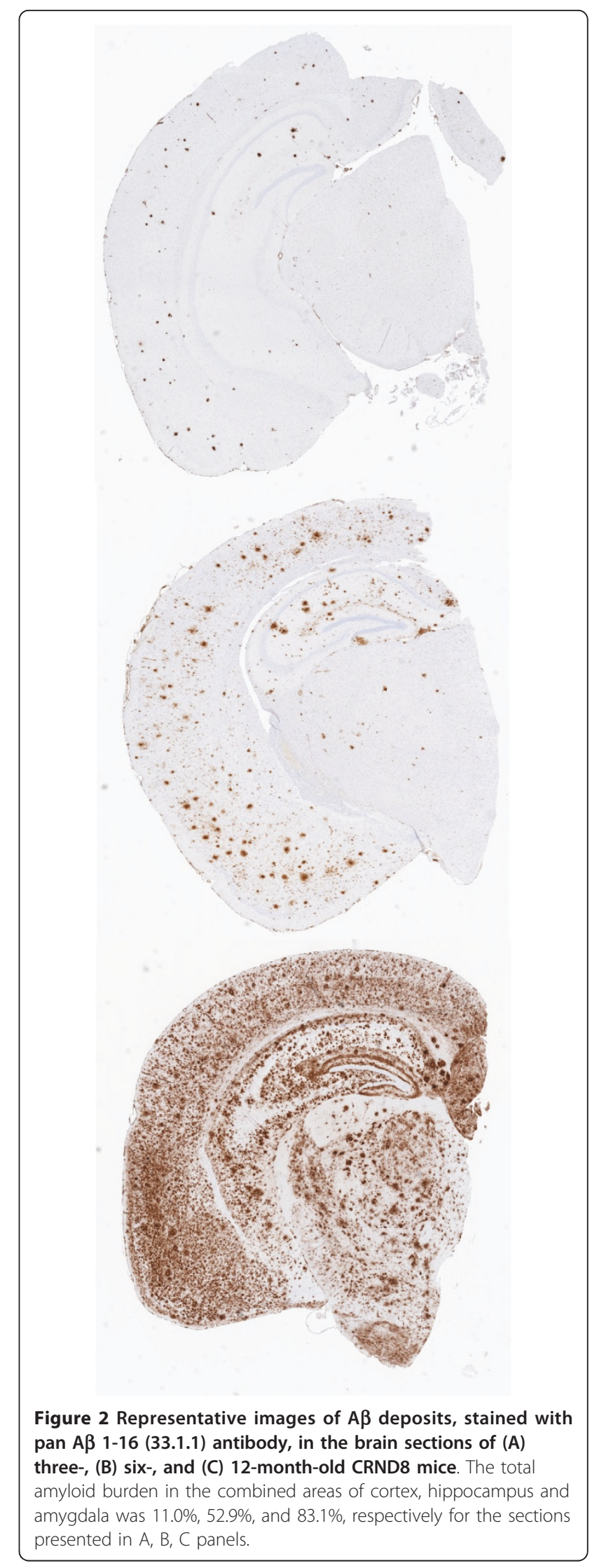




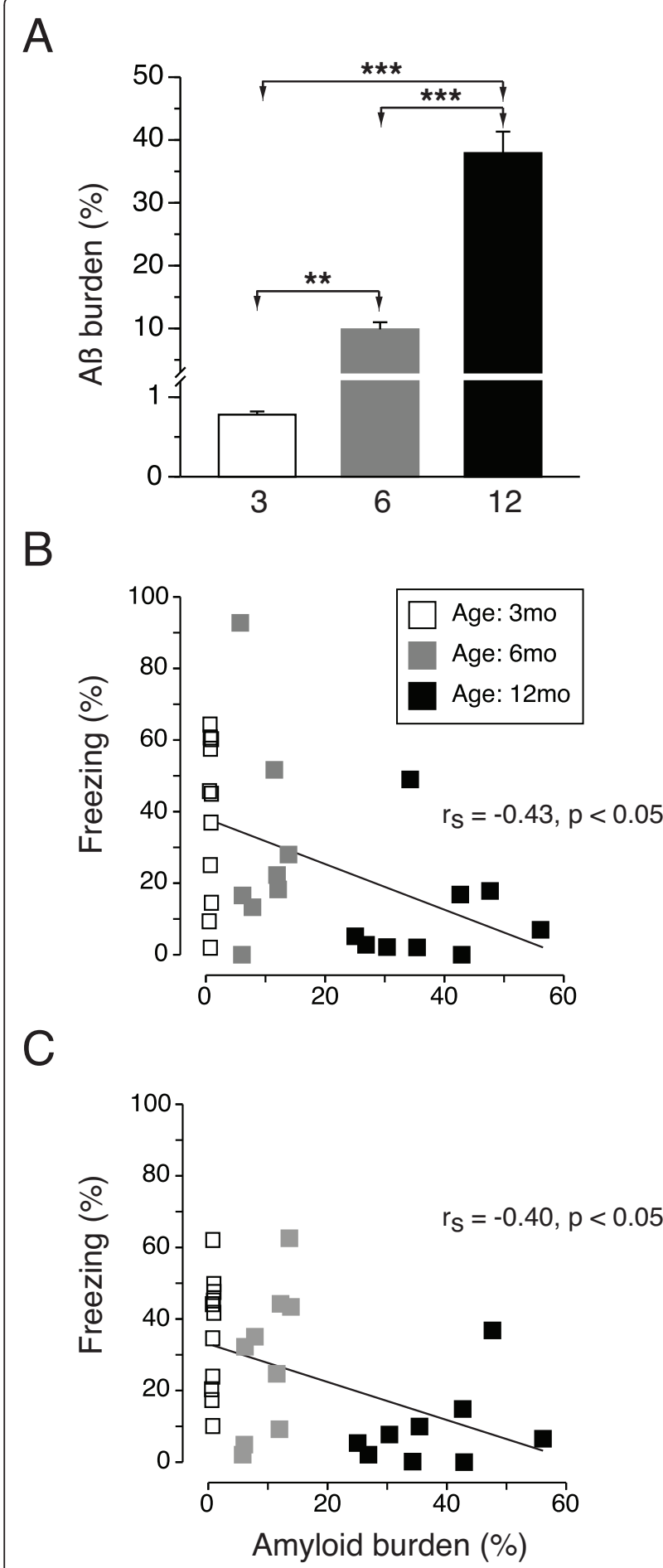

Figure 3 Amyloid- $\beta$ plaque burden and conditioned fear memory in CRND8 mice. (A) The levels of amyloid- $\beta$ burden (mean (\%) \pm SEM) significantly increased in CRND8 mice between the ages of three and 12 months. The progressing with age $A \beta$ plaque burden was significantly associated with deterioration in (B) contextual $(P<0.05)$ and in $(\mathbf{C})$ tone $(P<0.05)$ fear memory in CRND8 mice. ${ }^{* *} P<0.01$, *** $P<0.001$. age of 12 months $(70 \%, 93 \%, 144 \%$, and 53\%, 75\%, 113\% for three, six, and 12 month context and tone memory, respectively). While our analysis revealed no significant association between the $\mathrm{A} \beta$ plaque burden and the context fear memory in CRND8 mice at any age of testing, surprisingly, we found positive associations between $\mathrm{A} \beta$ plaque burden and tone fear memory at three $\left(\mathrm{r}_{S}=0.67\right.$, $P<0.05)$ and six months of age $\left(\mathrm{r}_{S}=0.80, P<0.01\right)$, but not at 12 months of age $\left(r_{S}=0.30\right.$, NS). Despite a much reduced sample size, these post-hoc analyses revealed that at the ages of three and six months, which are characterized by rapid $A \beta$ plaque formation, those CRND8 mice which showed more $A \beta$ plaques, also showed higher tone fear memory. At present, these preliminary results have to be interpreted with caution. These findings should be replicated in future studies and the relationship between the soluble $A \beta$ and $A \beta$ sequestered in plaques, and also other processes, such as reactive gliosis and inflammatory responses should be systematically evaluated in order to elucidate further the relationship between amyloid- $\beta$ and cognition at the early stage of plaque formation.

\section{Discussion}

The present results extend previous studies showing that other APP mouse models exhibit impairment in fear conditioned memory, by demonstrating that this impairment is progressive and correlates well with overall $\mathrm{A} \beta$ burden. Also, the demonstrated greater sensitivity of the foreground tone conditioning test in the identification of age dependent onset of the memory impairment in CRND8, suggests that this testing paradigm might be particularly suitable in studies evaluating potential therapeutic agents related to memory improvement in APP mouse models.

APP transgenic mouse models have been reported to show memory deficits similar to those observed in AD [21,48-53]. However, comprehensive cognitive profiles, including multiple memory systems, have often been based on comparative analyses from several independent studies using APP mouse models (see [21]). In our study, we simultaneously evaluated two memory systems; memory of the association between the context of the training environment and a foot-shock, which depends on the hippocampus, and memory of the association between a tone and a foot-shock, which is dependent on an intact amygdala. The strength of both types of memory in this paradigm is inferred from the same behavior of freezing response to relevant conditioned stimuli. The implementation of the delay fear conditioning paradigm, in which an explicit cue such as a tone is co-terminated with a foot-shock, usually results in stronger foreground conditioning to tone and weaker conditioning to background contextual cues [54]. Our 
study confirmed this prediction and demonstrated that $\mathrm{nTg}$ control mice had a stronger conditioned tone fear memory than a context fear memory. In contrast, the foreground fear conditioning to tone did not differentiate the response of CRND8 mice from their response to the background context cues. The apparent dissociation in the onset of the cognitive impairment of CRND8 mice in the delay conditioning paradigm has important practical consequences. First, it stresses the importance of the comparative analysis between genotypes across multiple tasks, which differ in the strength of memory development, in order to identify the ceiling performance or maximum dynamic range of the control $\mathrm{nTg}$ mice maintained on a specific genetic background. Second, the comparison between the tasks demonstrated that not only the impairment of CRND8 mice declined with age, but they also were not able to reach a level of performance comparable to $\mathrm{nTg}$ controls at the earlier ages of testing when the $A \beta$ plaque burden was relatively low. Moreover, the CRND8 mice showed impairment in generalizing the conditioning effects to additional cues present in the testing room, such as characteristics of sound attenuating chambers or other subtle cues, which despite our effort, could not be completely eliminated during the tone test. Consequently, their freezing rates during the pre-tone phase of the test were significantly lower than the freezing of $\mathrm{nTg}$ littermates, especially at older ages. Our results also indicated that the 12-month-old nTg control mice showed slightly lower, albeit not significant, freezing rates. Although aged, 19- to 20-month-old, C57BL/6 mice show impairment in the fear conditioning memories [55], additional studies should establish whether the decrease in the fear conditioned freezing response occurs reliably at much earlier ages in the hybrid $\mathrm{C} 57 \mathrm{BL} / 6 / / \mathrm{C} 3 \mathrm{H}$ background of the CRND8 model. Future studies should also extend our findings and focus on testing the CRND8 mice at ages preceding overt amyloid- $\beta$ deposition, in an attempt to elucidate whether the impairment in conditioned fear memory in this model contains an age-independent component [56], caused by the constitutive expression of the APP transgene. It has been demonstrated that fear memory in another APP Tg2576 mouse model was impaired before the first detection of soluble oligomeric $A \beta$ species $[57,58]$, which seems to support this hypothesis. In summary, our results show that at 12 months of age the CRND8 mice are significantly impaired in both context and cue fear memory, regardless of the salience of the available conditional stimuli, and that the sensitivity of the delay fear conditioning paradigm to identify the onset of impairment depended on the dynamic range of responses shown by control littermates to more salient foreground tone conditioning. The increased salience of the tone conditioned stimulus, which immediately preceded the foot-shock, resulted in greater sensitivity of the detection of memory deficiency in CRND8 mice due to the stronger shift of the nTg mice to the salience of foreground (tone) stimulus. By inference, our results indicate that the compromised hippocampal-amygdala function in CRND8 mice likely impaired the processing and the use of the more salient conditional tone stimulus $[59,60]$. It is likely, then, that the impairment in the detection of the salience of the foreground (tone) stimulus reflects subtle differences in the learning ability of CRND8 mice at early stages of amyloid pathology.

The comparable context fear memory of the genotypes at three and six months contrasts with the results of our previous studies which demonstrated significant impairment of CRND8 mice in the hippocampus-dependent spatial reference memory evaluated in the water maze test at these ages [26,38]. This discrepancy can be reconciled since the spatial reference memory evaluated in the water or Barnes mazes is not associated with contextual fear memory $[61,62]$ and each of these distinct types of memories might have different underlying mechanisms [63], following different biological functions and adaptive significance. It is also likely that the change in the salience of the conditioning context $[64,65]$ or switching the context conditioning from background to foreground, by eliminating the delay component of tone presentation, might increase the sensitivity of the context testing paradigm in identifying the impairment of the CRND8 mice in this type of memory at earlier ages. The advantage of the fear conditioning testing paradigm lies in its rapid development of robust and long-lasting memory, which is based on an evolutionary anti-predatory fear response preserved across many species, including humans. This paradigm, with its long lasting memory of the CS-US association provides easier implementation of tests focusing on memory acquisition, forgetting and extinction, and it is less physically demanding than the water maze test.

Our study also confirmed the early age of onset [38], followed by rapidly progressing $A \beta$ deposition in CRND8 mice. The deposition of $A \beta$ plaques increased about 12 -fold between three- and six-month and fourfold between six- and 12-month-old mice. This increase in $A \beta$ plaque burden was significantly correlated with the decline in contextual and tone fear memory. The importance of these results lies in the validation of the CRND8 model as a research tool which is sensitive to reveal the relationship between $A \beta$ accumulation and cognitive function, with the potential to evaluate the efficacy of pre-clinical therapeutic approaches aiming at improvement of the cognitive function.

There is considerable controversy related to the functional link between the insoluble $A \beta$ residing in plaques 
and cognitive dysfunction in AD [66-69] or in normal aged individuals [70]. However, the available post mortem evidence indicates significant associations between amyloid pathology and cognition in $\mathrm{AD}$ patients [6,71-73], with total amyloid load or burden being the most reliable and powerful manifestation of clinically diagnosed dementia [74]. While A $\beta$ plaque burden does not likely represent the immediate causal factor underlying dementia, our results suggest that it might be a robust surrogate marker indicating the severity of the impairment, at least in the fear conditioning paradigm applied in pre-clinical research using mouse models.

\section{Conclusions}

The advantage of applying the fear conditioning paradigm to evaluate cognitive dysfunction in human studies is that the test focuses on nondeclarative, unconscious memory, which depends on frontal and temporal regions, including cortical sensory processing areas, the thalamus, and the amygdala [75-77]. Several studies demonstrated that in humans fear conditioned memory also depends on the same neural structures that are affected at the early stage of AD [78-81]. Also, unlike declarative or conscious memory, nondeclarative, implicit memory depends less on subjective recall and recognition of information [82,83], providing a better comparative platform between pre-clinical studies involving animal models, and clinical studies of human dementia with neurodegeneration. Although few studies have demonstrated that fear conditioned memory is impaired in $\mathrm{AD}$ [84] and in frontotemporal lobar degeneration [85] (of note, an unconditional stimulus used in these studies was a one second burst of $100 \mathrm{db}$ white noise presented through headphones), the association between the impairment in implicit memory and amyloid plaque load in AD patients assessed in vivo [86] has yet to be addressed.

\footnotetext{
Abbreviations

AD: Alzheimer's disease; AB: amyloid beta; ANOVA: analysis of variance; APP: amyloid precursor protein; CR: conditioned response; CS: conditioned stimulus; CSF: cerebrospinal fluid; CV: coefficient of variation; c.p.s: clicks per second; FA: formic acid; FC: fear conditioning; NS: non-significant; nTg: nontransgenic mice; SEM: standard error of the mean; SDS: sodium dodecyl sulfate; Tg: transgenic mice; UR: unconditioned response; US: unconditioned stimulus.
}

\section{Acknowledgements}

We thank Dr. David Borchelt for comments, suggestions, and corrections of previous drafts of the manuscript.

\section{Author details}

${ }^{1}$ Center for Translational Research in Neurodegenerative Disease and Department of Neuroscience, University of Florida, 1275 Center Dr., Gainesville, FL, 32610, USA. ${ }^{2}$ Department of Neuroscience, Mayo Clinic, 4500 San Pablo Rd., Jacksonville, FL, 32224, USA. ${ }^{3}$ Neurobiology Division, The Roslin Institute and R(D)SVS, University of Edinburgh, Easter Bush, Midlothian, EH25 9RG, UK.

\section{Authors' contributions}

CJ conceived and supervised the study, analyzed the data and prepared the manuscript. $\mathrm{AH}$ and $\mathrm{KI}$ prepared the mice and executed the behavioral experiments, collected the data, and performed the evaluation of $A B$ burden. PD participated in the A $\beta$ staining. DD designed and carried out the brain sectioning, staining, and preparation of brain slices for the analyses. TG provided the mice and participated in the revision of the manuscript. All authors read and approved the final manuscript.

\section{Competing interests}

The authors declare that they have no competing interests.

Received: 27 March 2012 Revised: 11 June 2012

Accepted: 14 June 2012 Published: 14 June 2012

\section{References}

1. Alzheimer's Disease International: World Alzheimer Report 2009 Executive Summary.[http://www.alz.co.uk/research/files/ WorldAlzheimerReport-ExecutiveSummary.pdf].

2. Delacourte A: Tau pathology and neurodegeneration: an obvious but misunderstood link. J Alzheimers Dis 2008, 14:437-440.

3. Hardy J: The relationship between amyloid and tau. J Mol Neurosci 2003, 20:203-206.

4. Price $\mathrm{JL}$, Davis PB, Morris JC, White $\mathrm{DL}$ : The distribution of tangles, plaques and related immunohistochemical markers in healthy aging and Alzheimer's disease. Neurobiol Aging 1991, 12:295-312.

5. Selkoe DJ: Normal and abnormal biology of the $\beta$-amyloid precursor protein. Annu Rev Neurosci 1994, 17:489-517.

6. Braak H, Braak E: Neuropathological stageing of Alzheimer-related changes. Acta Neuropathol (Berl) 1991, 82:239-259.

7. Braak H, Braak E: Pathology of Alzheimer's disease. In Neurodegenerative Diseases. Edited by: Calne DB. Philadelphia: Saunders; 1994:585-613.

8. Braak H, Braak E: Diagnostic criteria for neuropathologic assessment of Alzheimer's disease. Neurobiol Aging 1997, 18:585-88.

9. Hooper MW, Vogel FS: The limbic system in Alzheimer's disease. Am J Pathol 1976, 85:1-20.

10. Almkvist O, Winblad B: Early diagnosis of Alzheimer dementia based on clinical and biological factors. Eur Arch Psychiatry Clin Neurosci 1999, 249(Suppl 3):3-9.

11. Braak H, Braak E: Frequency of stages of Alzheimer-related lesions in different age categories. Neurobiol Aging 1997, 18:351-357.

12. Cairns NJ, Chadwick A, Luthert PJ, Lantos PL: beta-Amyloid protein load is relatively uniform throughout neocortex and hippocampus in elderly Alzheimer's disease patients. Neuroscience Lett 1991, 129:115-118.

13. de la Torre JC: Pathophysiology of neuronal energy crisis in Alzheimer's disease. Neurodegener Dis 2008, 5:126-132.

14. den Heijer T, Geerlings Ml, Hoebeek FE, Hofman A, Koudstaal PJ, Breteler MM: Use of hippocampal and amygdalar volumes on magnetic resonance imaging to predict dementia in cognitively intact elderly people. Arch Gen Psychiatry 2006, 63:57-62.

15. Kril JJ, Patel S, Harding AJ, Halliday GM: Neuron loss from the hippocampus of Alzheimer's disease exceeds extracellular neurofibrillary tangle formation. Acta Neuropathol (Berl) 2002, 103:370-376.

16. Sze Cl, Troncoso JC, Kawas C, Mouton P, Price DL, Martin L: Loss of the presynaptic vesicle protein synaptophysin in hippocampus correlates with cognitive decline in Alzheimer disease. I Neuropathol Exp Neurol 1997, 56:933-944.

17. Tapiola T, Pennanen C, Tapiola M, Tervo S, Kivipelto M, Hanninen T, Pihlajamaki M, Laakso MP, Hallikainen M, Hamalainen A, Vanhanen M, Helkala EL, Vanninen R, Nissinen A, Rossi R, Frisoni GB, Soininen H: MRI of hippocampus and entorhinal cortex in mild cognitive impairment: a follow-up study. Neurobiol Aging 2008, 29:31-38.

18. West MJ, Coleman PD, Flood DG, Troncoso JC: Differences in the pattern of hippocampal neuronal loss in normal ageing and Alzheimer's disease. Lancet 1994, 344:769-772.

19. Ashe KH: Mechanisms of memory loss in Abeta and tau mouse models. Biochem Soc Trans 2005, 33:591-594

20. Dodart JC, Mathis C, Bales KR, Paul SM: Does my mouse have Alzheimer's disease? Genes, Brain Behav 2002, 1:142-155.

21. Eriksen JL, Janus CG: Plaques, tangles, and memory loss in mouse models of neurodegeneration. Behav Genet 2007, 37:79-100. 
22. Price DL, Sisodia SS: Mutant genes in familial Alzheimer's disease and transgenic models. Annu Rev Neurosci 1998, 21:479-505.

23. Seabrook GR, Rosahl TW: Transgenic animals relevant to Alzheimer's disease. Neuropharmacology 1999, 38:1-17.

24. Hanna A, Horne P, Yager D, Eckman C, Eckman E, Janus C: Amyloid beta and impairment in multiple memory systems in older transgenic APP TgCRND8 mice. Genes Brain Behav 2009, 8:676-684.

25. Janus C: Search strategies used by APP transgenic mice during navigation in the Morris water maze. Learn Mem 2004, 11:337-346.

26. Janus C, Pearson J, McLaurin J, Mathews PM, Jiang Y, Schmidt SD, Chishti MA, Horne P, Heslin D, French J, Mount HT, Nixon RA, Mercken M, Bergeron C, Fraser PE, St George-Hyslop P, Westaway D: A beta peptide immunization reduces behavioural impairment and plaques in a model of Alzheimer's disease. Nature 2000, 408:979-982.

27. Lovasic $L$, Bauschke $H$, Janus C: Working memory impairment in a transgenic amyloid precursor protein TgCRND8 mouse model of Alzheimer's disease. Genes Brain Behav 2005, 4:197-208.

28. Janus C, Welzl H, Hanna A, Lovasic L, Lane N, St George-Hyslop P, Westaway D: Impaired conditioned taste aversion learning in APP transgenic mice. Neurobiol Aging 2004, 25:1213-1219.

29. Ambree O, Touma C, Gortz N, Keyvani K, Paulus W, Palme R, Sachser N: Activity changes and marked stereotypic behavior precede Abeta pathology in TgCRND8 Alzheimer mice. Neurobiol Aging 2006, 27:955-964.

30. Dudal S, Krzywkowski P, Paquette J, Morissette C, Lacombe D, Tremblay P, Gervais F: Inflammation occurs early during the Abeta deposition process in TgCRND8 mice. Neurobiol Aging 2004, 25:861-871.

31. Del Vecchio RA, Gold LH, Novick SJ, Wong G, Hyde LA: Increased seizure threshold and severity in young transgenic CRND8 mice. Neurosci Lett 2004, 367:164-167.

32. Fanselow MS: Contextual fear, gestalt memories, and the hippocampus. Behav Brain Res 2000, 110:73-81.

33. LeDoux JE, Sakaguchi A, Iwata J, Reis DJ: Interruption of projections from the medial geniculate body to an archi-neostriatal field disrupts the classical conditioning of emotional responses to acoustic stimuli. Neuroscience 1986, 17:615-627.

34. Chen G, Wang LP, Tsien JZ: Neural population-level memory traces in the mouse hippocampus. PLoS One 2009, 4:e8256.

35. Logue SF, Paylor R, Wehner JM: Hippocampal lesions cause learning deficits in inbred mice in the Morris water maze and conditioned-fear task. Behav Neurosci 1997, 111:104-113.

36. Phillips RG, LeDoux JE: Differential contribution of amygdala and hippocampus to cued and contextual fear conditioning. Behav Neurosci 1992, 106:274-285.

37. Schafe GE, Nader K, Blair HT, LeDoux JE: Memory consolidation of Pavlovian fear conditioning: a cellular and molecular perspective. Trends Neurosci 2001, 24:540-546.

38. Chishti MA, Yang DS, Janus C, Phinney AL, Horne P, Pearson J, Strome R, Zuker N, Loukides J, French J, Turner S, Lozza G, Grilli M, Kunicki S, Morissette C, Paquette J, Gervais F, Bergeron C, Fraser PE, Carlson GA, George-Hyslop PS, Westaway D: Early-onset amyloid deposition and cognitive deficits in transgenic mice expressing a double mutant form of amyloid precursor protein 695. J Biol Chem 2001, 276:21562-21570.

39. Selkoe DJ: Alzheimer's Disease: genotypes, phenotypes, and treatments. Science 1997, 275:630-631.

40. Chartier-Harlin M-C, Crawford F, Houlden H, Warren A, Hughes D, Fidani L, Goate A, Rossor M, Roques P, Hardy J, Mullan M: Early-onset Alzheimer's Disease caused by mutations at codon 717 of the $\beta$-amyloid precursor protein gene. Nature 1991, 353:844-846.

41. Rogers DC, Fisher EM, Brown SD, Peters J, Hunter AJ, Martin JE: Behavioral and functional analysis of mouse phenotype: SHIRPA, a proposed protocol for comprehensive phenotype assessment. Mamm Genome 1997, 8:711-713.

42. Rogers DC, Jones DN, Nelson PR, Jones CM, Quilter CA, Robinson TL, Hagan JJ: Use of SHIRPA and discriminant analysis to characterise marked differences in the behavioural phenotype of six inbred mouse strains. Behav Brain Res 1999, 105:207-217.

43. Fanselow MS: Factors governing one-trial contextual conditioning. Anim Learn Behav 1990, 18:264-270.

44. Franklin KBJ, Paxinos G: The Mouse Brain in Stereotaxic Coordinates. 3 edition. New York: Elsevier/Academic Press; 2007.
45. Ruifrok AC, Johnston DA: Quantification of histochemical staining by color deconvolution. Anal Quant Cytol Histol 2001, 23:291-299.

46. Howell DC: Statistical Methods for Psychology Belmont, California: Duxbury Press; 1992

47. Siegel S, Castellan JNJ: Nonparametric Statistics for Behavioral Sciences New York: McGraw-Hill Book Company; 1988.

48. Bayer TA, Wirths O: Review on the APP/PS1KI mouse model: intraneuronal Abeta accumulation triggers axonopathy, neuron loss and working memory impairment. Genes Brain Behav 2008, 7(Suppl 1):6-11.

49. Dewachter I, van Dorpe J, Spittaels K, Tesseur I, Van Den Haute C, Moechars D, Van Leuven F: Modeling Alzheimer's disease in transgenic mice: effect of age and of presenilin 1 on amyloid biochemistry and pathology in APP/London mice. Exp Gerontol 2000, 35:831-841.

50. Gimenez-Llort L, Blazquez G, Canete T, Johansson B, Oddo S, Tobena A, LaFerla FM, Fernandez-Teruel A: Modeling behavioral and neuronal symptoms of Alzheimer's disease in mice: a role for intraneuronal amyloid. Neurosci Biobehav Rev 2007, 31:125-147.

51. Gotz J, Ittner LM: Animal models of Alzheimer's disease and frontotemporal dementia. Nat Rev Neurosci 2008, 9:532-544.

52. McGowan E, Eriksen J, Hutton M: A decade of modeling Alzheimer's disease in transgenic mice. Trends Genet 2006, 22:281-289.

53. Spires TL, Hyman BT: Transgenic models of Alzheimer's disease: learning from animals. NeuroRx 2005, 2:423-437.

54. Radulovic J, Kammermeier J, Spiess J: Generalization of fear responses in C57BL/6N mice subjected to one-trial foreground contextual fear conditioning. Behav Brain Res 1998, 95:179-189.

55. Gould TJ, Feiro OR: Age-related deficits in the retention of memories for cued fear conditioning are reversed by galantamine treatment. Behav Brain Res 2005, 165:160-171.

56. Chen G, Chen KS, Knox J, Inglis J, Bernard A, Martin SJ, Justice A, McConlogue L, Games D, Freedman SB, Morris RG: A learning deficit related to age and beta-amyloid plaques in a mouse model of Alzheimer's disease. Nature 2000, 408:975-979.

57. Dineley KT, Xia X, Bui D, Sweatt JD, Zheng H: Accelerated plaque accumulation, associative learning deficits, and up-regulation of alpha 7 nicotinic receptor protein in transgenic mice co-expressing mutant human presenilin 1 and amyloid precursor proteins. J Biol Chem 2002, 277:22768-22780.

58. Jacobsen JS, Wu CC, Redwine JM, Comery TA, Arias R, Bowlby M, Martone R, Morrison JH, Pangalos MN, Reinhart PH, Bloom FE: Early-onset behavioral and synaptic deficits in a mouse model of Alzheimer's disease. Proc Natl Acad Sci USA 2006, 103:5161-5166.

59. Desmedt A, Garcia R, Jaffard R: An 8-day extensive elemental, but not contextual, fear conditioning potentiates hippocampal-lateral septal synaptic efficacy in mice. Synapse 2003, 49:270-278.

60. Desmedt A, Marighetto A, Garcia R, Jaffard R: The effects of ibotenic hippocampal lesions on discriminative fear conditioning to context in mice: impairment or facilitation depending on the associative value of a phasic explicit cue. Eur J Neurosci 2003, 17:1953-1963.

61. Bach ME, Hawkins RD, Osman M, Kandel ER, Mayford M: Impairment of spatial but not contextual memory in CaMKII mutant mice with a selective loss of hippocampal LTP in the range of the theta frequency. Cell 1995, 81:905-915.

62. d'Isa R, Clapcote SJ, Voikar V, Wolfer DP, Giese KP, Brambilla R, Fasano S: Mice lacking Ras-GRF1 show contextual fear conditioning but not spatial memory impairments: convergent evidence from two independently generated mouse mutant lines. Front Behav Neurosci 2011, 5:78.

63. Mizuno K, Giese KP: Hippocampus-dependent memory formation: do memory type-specific mechanisms exist? J Pharmacol Sci 2005, 98:191-197.

64. Corcoran KA, Lu Y, Turner RS, Maren S: Overexpression of hAPPswe impairs rewarded alternation and contextual fear conditioning in a transgenic mouse model of Alzheimer's disease. Learn Mem 2002, 9:243-252.

65. Frankland PW, Josselyn SA, Anagnostaras SG, Kogan JH, Takahashi E, Silva AJ: Consolidation of CS and US representations in associative fear conditioning. Hippocampus 2004, 14:557-569.

66. Terry RD: The pathogenesis of Alzheimer disease: an alternative to the amyloid hypothesis. J Neuropathol Exp Neurol 1996, 55:1023-1025. 
67. Masliah E, Terry RD, Mallory M, Alford M, Hansen LA: Diffuse plaques do not accentuate synapse loss in Alzheimer's disease. Am J Pathol 1990, 137:1293-1297.

68. Einstein $G$, Buranosky $R$, Crain BJ: Dendritic pathology of granule cells in Alzheimer's disease is unrelated to neuritic plaques. J Neurosci 1994, 14:5077-5088.

69. Hyman BT, Marzloff K, Arriagada PV: The lack of accumulation of senile plaques or amyloid burden in Alzheimer's disease suggests a dynamic balance between amyloid deposition and resolution. J Neuropathol Exp Neurol 1993, 52:594-600.

70. Rentz DM, Locascio JJ, Becker JA, Moran EK, Eng E, Buckner RL, Sperling RA, Johnson KA: Cognition, reserve, and amyloid deposition in normal aging. Ann Neurol 2010, 67:353-364.

71. Naslund J, Haroutunian V, Mohs R, Davis KL, Davies P, Greengard P, Buxbaum JD: Correlation between elevated levels of amyloid betapeptide in the brain and cognitive decline. JAMA 2000, 283:1571-1577.

72. Bancher C, Braak H, Fischer P, Jellinger KA: Neuropathological staging of Alzheimer lesions and intellectual status in Alzheimer's and Parkinson's disease patients. Neurosci Lett 1993, 162:179-182.

73. Thal DR, Holzer M, Rub U, Waldmann G, Gunzel S, Zedlick D, Schober R: Alzheimer-related tau-pathology in the perforant path target zone and in the hippocampal stratum oriens and radiatum correlates with onset and degree of dementia. Exp Neurol 2000, 163:98-110.

74. Cummings BJ, Cotman CW: Image analysis of beta-amyloid load in Alzheimer's disease and relation to dementia severity. Lancet 1995, 346:1524-1528.

75. Kim JJ, Rison RA, Fanselow MS: Effects of amygdala, hippocampus, and periaqueductal gray lesions on short-term and long-term contextual fear. Beh Neurosci 1993, 107:1093-1098.

76. LeDoux JE: Emotion, memory and the brain. Sci Am 1994, 270:50-57.

77. LeDoux JE: Emotion circuits in the brain. Annu Rev Neurosci 2000, 23:155-184.

78. Bechara A, Damasio H, Damasio AR, Lee GP: Different contributions of the human amygdala and ventromedial prefrontal cortex to decisionmaking. J Neurosci 1999, 19:5473-5481.

79. Bechara A, Tranel D, Damasio H, Adolphs R, Rockland C, Damasio AR: Double dissociation of conditioning and declarative knowledge relative to the amygdala and hippocampus in humans. Science 1995, 269:1115-1118.

80. Buchel C, Dolan RJ: Classical fear conditioning in functional neuroimaging. Curr Opin Neurobiol 2000, 10:219-223.

81. Phelps EA: Human emotion and memory: interactions of the amygdala and hippocampal complex. Curr Opin Neurobiol 2004, 14:198-202.

82. Squire LR: Memory and the hippocampus: a synthesis from findings with rats, monkeys, and humans. Psychol Rev 1992, 99:195-231.

83. Squire LR: Memory systems of the brain: a brief history and current perspective. Neurobiol Learn Mem 2004, 82:171-177.

84. Hamann S, Monarch ES, Goldstein FC: Impaired fear conditioning in Alzheimer's disease. Neuropsychologia 2002, 40:1187-1195.

85. Hoefer M, Allison SC, Schauer GF, Neuhaus JM, Hall J, Dang JN, Weiner MW Miller BL, Rosen $\mathrm{HJ}$ : Fear conditioning in frontotemporal lobar degeneration and Alzheimer's disease. Brain 2008, 131:1646-1657.

86. de Souza LC, Corlier F, Habert MO, Uspenskaya O, Maroy R, Lamari F, Chupin M, Lehericy S, Colliot O, Hahn-Barma V, Samri D, Dubois B, Bottlaender M, Sarazin M: Similar amyloid-beta burden in posterior cortical atrophy and Alzheimer's disease. Brain 2011, 134:2036-2043.

doi:10.1186/alzrt124

Cite this article as: Hanna et al:: Age-related increase in amyloid plaque burden is associated with impairment in conditioned fear memory in CRND8 mouse model of amyloidosis. Alzheimer's Research \& Therapy 2012 $4: 21$.

\section{Submit your next manuscript to BioMed Central and take full advantage of:}

- Convenient online submission

- Thorough peer review

- No space constraints or color figure charges

- Immediate publication on acceptance

- Inclusion in PubMed, CAS, Scopus and Google Scholar

- Research which is freely available for redistribution

Submit your manuscript at www.biomedcentral.com/submit 